\title{
STREAM DEPTH SIGNIFICANCE DURING IN-SITU SEDIMENT OXYGEN DEMAND MEASUREMENTS IN SHALLOW STREAMS
}

Anf H. Ziadat

Bruce W. Berdanier

Fairfield University, bberdanier@fairfield.edu

Follow this and additional works at: https://digitalcommons.fairfield.edu/engineering-facultypubs Copyright 2004 Wiley for American Water Resources Association.

\section{Repository Citation}

Ziadat, Anf $\mathrm{H}$. and Berdanier, Bruce W., "STREAM DEPTH SIGNIFICANCE DURING IN-SITU SEDIMENT OXYGEN DEMAND MEASUREMENTS IN SHALLOW STREAMS" (2004). Engineering Faculty Publications. 35.

https://digitalcommons.fairfield.edu/engineering-facultypubs/35

\section{Published Citation}

Ziadat, Anf H., and Bruce W. Berdanier. "STREAM DEPTH SIGNIFICANCE DURING IN-SITU SEDIMENT OXYGEN DEMAND MEASUREMENTS IN SHALLOW STREAMS." JAWRA Journal of the American Water Resources Association 40, no. 3 (2004): 631-638.

This item has been accepted for inclusion in DigitalCommons@Fairfield by an authorized administrator of DigitalCommons@Fairfield. It is brought to you by DigitalCommons@Fairfield with permission from the rightsholder(s) and is protected by copyright and/or related rights. You are free to use this item in any way that is permitted by the copyright and related rights legislation that applies to your use. For other uses, you need to obtain permission from the rights-holder(s) directly, unless additional rights are indicated by a Creative Commons license in the record and/or on the work itself. For more information, please contact digitalcommons@fairfield.edu. 


\title{
Stream Depth Significance During In-situ Sediment Oxygen \\ Demand Measurements in Shallow Streams \\ Anf H. Ziadat, Bruce W. Berdanier*
}

\begin{abstract}
Ninety-one sediment oxygen demand samples from six designated sites along the stretch of Lower Rapid Creek, South Dakota were conducted using an in-situ sediment oxygen demand chamber. Inside the chamber, readings of dissolved oxygen, water temperature, $\mathrm{pH}$, and specific conductance were recorded every one-minute for more than one hour using the Datasonde 3 Hydrolab. Initial readings of such parameters were recorded for the overlaying water before the deployment of the SOD chamber. Characteristics of the stream conditions, air temperature, barometric pressure, average flow velocity of the stream, depth of the stream, and the flow velocity by the chamber were recorded. Single and multiple linear regression analysis on all parameters indicated that the velocity of the stream is the least critical parameter for sediment oxygen demand in shallow streams.
\end{abstract}

Key words - sediment oxygen demand (SOD) chamber, surface water quality, oxygen depletion, benthic layer, ANOVA statistical analysis, stream depth.

*Dr. Anf H. Ziadat is an Assistant Professor of Civil and Environmental Engineering at Mutah University, College of Engineering, PO Box 67, Mutah, Al-Karak, Jordan 61710.

*Dr. Bruce W. Berdanier is an Associate Professor of Civil Engineering at Ohio Northern University, 525 South Main Street, Ada, Ohio 45810. 


\section{INTRODUCTION}

This research focused on measuring the Sediment Oxygen Demand (SOD) in different reaches of a shallow stream and evaluating the impact of different variables on the benthic SOD. In-situ Sediment Oxygen Demand measurement techniques should provide the most accurate means to obtain ambient conditions, introducing less error due to handling than laboratory methods. The primary obstacle to in-situ measurements is that researchers must overcome a variety of natural conditions. For example, the influence of weather conditions determines when, and how long, measurements can be taken (Bowman and Delfino, 1980). In comparison with other techniques, research has shown that the in-situ method provides the most accurate technique for measuring SOD (Murphy and Hicks 1986, Edderg and Hofsten, 1972).

In-Situ Sediment Oxygen Demand was measured during 91 sampling events distributed across six sampling stations along Lower Rapid Creek, South Dakota during the mid summer months (July-August) of the year 2000 (See Figure 1). The sites used in this research had been previously chosen as the sites to be used to characterize this length of the Rapid Creek for establishing a Total Maximum Daily Load (TMDL). Therefore, the six sites had been carefully chosen to establish a clear picture of the impact due to a variety of land uses.

There are no standard procedures or equipment for measuring SOD rates, but the methodology employed for in-situ measurement involves enclosing a known area of sediment inside a respiration chamber of a known volume, usually with the water circulating inside, while dissolved oxygen depletion is measured over a period of time. The time of measurement is influenced by the rate of oxygen uptake, residual D.O., and other factors. 


\section{SITE DESCRIPTION}

Rapid Creek is one of the most important streams in the western part of South Dakota, originating near Crooks Tower in the Black Hills west of Rapid City and terminating after 129 river miles at the Cheyenne River (Figure 1). Rapid Creek serves as a valuable resource to the area by providing water for recreation, irrigation, and a significant part of the municipal water supply for the City of Rapid City. The flow in Rapid Creek is regulated by Deerfield and Pactola reservoirs, which provide flood control, irrigation, and municipal water for downstream areas. Rapid Creek provides irrigation water for approximately 8,900 acres of agricultural land primarily used to grow alfalfa, small grains, corn, and pasture for livestock feed supplies in Rapid Valley (Driscoll and Zogorski, 1990). During the last two decades the City of Rapid City has expanded in all directions, with more residential areas developed along Rapid creek upstream of Rapid City, as well as dramatic growth within the city limits. The majority of the new developed areas beyond the city limits are using septic tank systems, leading to more risk of seepage and contamination of surface water and ground water in the area. Deterioration of water quality along Rapid Creek has become more evident due to increased construction activity, and storm water discharge from urban areas (Goddard et.al, 1987).

Rapid Creek enters Rapid City from the west. The water quality is influenced by two point source pollutants; the Cleghorn Springs Fish Hatchery (CSFH) upstream, and the Rapid City Wastewater Treatment Plant located downstream from Rapid City. The nonpoint source pollutants included urban and rural runoff; such as sediments, nutrients, and bacteria. It is anticipated that the measured sediment oxygen demand values will vary from one sampling location to another depending on the land use along the stretch of the study area along with other factors such as sediment composition, grain size, etc. 
This article will focus on the relationship between water column and hydraulic considerations and the benthic SOD. Future articles will detail relationships between the sediment composition, macroinvertebrates, land use, etc. The following SOD sampling sites were used in the study: 1- Above Canyon Lake, 2- Below Hawthorn Ditch, 3- Above Wastewater Treatment Plant, 4- Below Wastewater Treatment Plant, 5- At Caputa, and 6- Near Farmingdale.

\section{SEDIMENT OXYGEN DEMAND CHAMBER SPECIFICATIONS}

A Sediment Oxygen Demand chamber made of stainless steel was used. The chamber is similar, with some modifications to the one used in the Tualatin River Basin, Oregon, (Rounds and Dolye, 1997). One of the main reasons for designing and manufacturing a modified chamber is to maintain the minimum disturbance possible to the sediment and its biological community under the same ambient conditions including the flow velocity of the stream inside the chamber. The stainless steel chamber was manufactured by Campbell Scientific Corporation, Canada and modified at South Dakota School of Mines and Technology, for this research.

The SOD chamber used in this research has a saw-tooth bottom edge to make a secure seal with the sediment bed by grinding it into the substrate. The dimensions of the chamber were chosen specific to the research needs of this project. The diameter of the chamber was chosen to be of sufficient size to accommodate sampling datasondes, mixing impeller, inspection ports and water evacuation valves. Further consideration was given to providing clearance between all openings for ease of operation and to minimize flow interferences with the mixing impeller. Additionally, the depth of the chamber was chosen to provide reasonable submergence for the anticipated depths in Rapid Creek during the project. The chamber is 23.5 inches in diameter and 12 inches in height. The bottom of the chamber is open and the top has two large inspection ports with hand-operated valves to emit water and the trapped air as the chamber is submerged 
through the water column in addition to another two ports for water quality instruments (Figure 2). The Datasonde 3, Submersible Water Quality Data Logger Hydrolab (SVR3-DL Surveyor 3 data logger) is inserted in one of the ports while the other port is used as a stand-by to fit the YSI 5700 series dissolved oxygen probe in the absence of the Hydro-lab. One of these two ports was typically closed while the chamber was in operation during the study. The chamber enclosed a volume of 70.68 liters and exposes an area of $0.28 \mathrm{~m}^{2}$ of sediment to the naturally circulating volume.

A double-sided stainless steel fan (eight blades outside, and five blades inside the chamber) supported on a 12-inch free rotation rod passing through the top of the chamber is the main source of water circulation inside the chamber (Figure 3). The natural current flow in the stream generated the rotation of the outside blades leading to a complete rotation of the inside blades which developed a circulation inside the chamber depending on the current velocity of the flow outside the chamber. This is a mechanically mixed operation developed by the movement of the water current itself outside the chamber. This design was chosen to provide close to natural environmental conditions in the sediment under the chamber by limiting disturbance and resuspension effect. In past studies, circulation has been developed inside the chamber by using a battery powered pumping system that could result in higher velocities and more scouring inside the chamber. The double-sided stainless steel fan designed for the chamber used in this research eliminated the need for an artificial pumping system inside the chamber adjusted to some estimated velocity. 


\section{SOD TESTING AND MEASUREMENT PROCEDURES}

Two people conducted the chamber deployment to the bottom of the creek using the chamber handles. The SOD sampling methodology used in this project is summarized as follows:

1. Calibrate the Datasonde 3 Hydrolab according to the operation manual. The initial calibration included dissolved oxygen, specific conductance, and $\mathrm{pH}$ standards 4,7 , and 10.

2. Apply the tag line to determine the length of the cross section of the creek and to provide a clear description of the location of the deployed chamber from the tag line as a reference from a permanent known structure (bridges, fences, etc.).

3. Conduct flow velocity measurement to determine the average velocity of the stream at the time of SOD sampling. A type AA-current meter was used to measure the velocity of the flow at the SOD chamber and also along the cross section of the creek near the tag line. Average cross section velocity was determined using standard methodology of the United States Geological Survey while data was being collected in the SOD chamber.

4. Deploy the chamber using the following sequence. Open the two release valves to emit water and the trapped air as the chamber is submerged through the water column. Push on the chamber and firmly insert, so the saw-tooth edge grinds into the substrate. Use a snooper (a device made in order to inspect the chamber under water), to ensure that all the saw teeth of the chamber are buried under the bed sediment. Allow approximately one inch of the sediment bed to cover over the saw teeth of the chamber. Take initial readings of surface water parameters by the chamber using the Hydro-lab probe. Insert the Hydro-lab probe into the designated port in the SOD chamber. Make sure that the Hydro-lab probe is deep enough inside the chamber. Use a screwdriver to tighten the 
clamp on the gasket, which holds the Hydro-lab probe to prevent leakage. Allow fifteen to twenty minutes before closing the release valves. Make sure the fan blades are rotating according to the flow in the stream. Start recording readings from the Hydro-lab every one-minute for one complete hour. The readings from the Hydro-lab would include dissolved oxygen, $\mathrm{pH}$, water temperature, and specific conductance.

5. Record air temperature and barometric pressure using a thermometer and a pressure gage.

6. Record gage height from the U.S.G.S gages if available to determine the instantaneous flow.

7. Upon completion of the test, check the Hydro-lab probe, and clean the chamber.

8. Relocate to the next sampling station; recalibrate the DO probe on the Hydro-lab at each new station because it is a function of the barometric pressure, which varies from one location to another.

Preventing any leak or openings between the chamber bottom and the sediment bed interface was the most crucial and difficult part of the operation. At some stations obtaining a proper seal was difficult due to the gravel and cobble bed sediments. The chamber was relocated within such cross sections until the seal between the chamber and the substrate of the stream was obtained.

\section{SEDIMENT OXYGEN DEMAND SAMPLING DATA AND ANALYSIS}

Ninety-one SOD sampling events from the six designated sites along the stretch of Lower Rapid Creek were conducted according to the SOD sampling and measurement procedures discussed above. Inside the chamber, readings of dissolved oxygen, water temperature, $\mathrm{pH}$, and specific conductance were recorded every one-minute for more than one hour using the 
Datasonde 3 Hydrolab. Also initial readings of such parameters were recorded for the overlaying water before the deployment of the SOD chamber. Characteristics of the stream conditions, air temperature, barometric pressure, average flow velocity of the stream, and the flow velocity by the chamber were recorded. Detailed results of all sampling events are presented in Ziadat's dissertation (Ziadat, 2000). During the study period, the average cross section velocity and the average velocity at the chamber compared as shown in Table 1.

\section{CALCULATIONS OF SEDIMENT OXYGEN DEMAND}

After the deployment of the sediment oxygen demand chamber to the bottom of the Creek, an initial rapid decrease in dissolved oxygen within the chamber became noticeable in the first 10-15 minutes. Such decrease in dissolved oxygen can be a result of a small amount of bottom sediment that had been suspended in the chamber during deployment and had not yet settled back to the sediment surface (resuspension). As discussed in the methodology above, readings were not initiated for the first 15 - 20 minutes after insertion of the chamber based on empirical observations to allow resettling of sediment. The slope of the sediment oxygen demand curve was developed by plotting the elapsed time versus the dissolved oxygen readings during each sampling event. Such values were recorded every one-minute, and a representative dissolved oxygen slope was established at each location for each sampling period. For demonstration purposes a typical graph is presented in Figure 4. The Sediment Oxygen Demand can be calculated using the following equation:

$$
\text { SOD }=1.44 *\{\mathrm{~V} / \mathrm{A}\} * \mathbf{b}
$$


Where :

SOD : Sediment Oxygen Demand Rate $\left(\mathrm{g} / \mathrm{m}^{2}\right.$.day $)$

b : Slope of the Oxygen Depletion Curve (mg /L .minute )

V : Volume of the chamber (liters)

A : Area of the bottom sediment covered by the chamber $\left(\mathrm{m}^{2}\right)$

1.44 : is a conversion factor from ( $\mathrm{mg} / \mathrm{min}$ ) to ( $\mathrm{g} /$ day )( Murphy and Hicks, 1986 )

Therefore, SOD at each site $=1.44 *\left\{70.68\right.$ liter $\left./ 0.28 \mathrm{~m}^{2}\right) *(\mathrm{~b})$

And, SOD calculated $=(363.50) *(b)$

\section{Relevant dimensional data for the SOD chamber used in this research were as follows:}

radius of the chamber $=0.30 \mathrm{~m}$, total height of the chamber $=0.30 \mathrm{~m}$, average height of chamber after inserted into the sediment $=0.25 \mathrm{~m}$, surface area of the chamber used $=0.28 \mathrm{~m}^{2}$, volume of the chamber $=70.68$ liter .

The slope of the oxygen depletion curves was calculated and used in equation (1) to determine the SOD values at each site. A summary of the obtained SOD values at the average measured temperature during the two months of sampling is presented in Table 2.

To standardize the SOD values under $20^{\circ} \mathrm{C}$, the following equation was applied:

$$
\operatorname{SOD}_{20}=\left\{\operatorname{SOD}_{\mathrm{T}}\right\} /\left\{\Theta^{\mathrm{T}-20}\right\}
$$

Where :

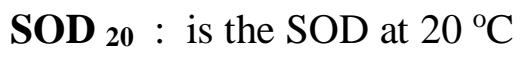

SOD $\mathrm{T}$ : is the measured SOD at temperature $\mathrm{T}\left({ }^{\circ} \mathrm{C}\right)$ 
$\Theta$ : is an accepted, empirically determined $(\theta=1.065)$ value for relating sediment oxygen demand values at standard conditions $\left(20^{\circ} \mathrm{C}\right)$ to field temperature conditions( Thomann and Muller, 1987 ).

In order to compare the SOD values obtained from the six sampling sites at a normalized temperature, the SOD measured values were adjusted to a standardized temperature of $20{ }^{\circ} \mathrm{C}$ according to equation (2). Table 3 presents the standardized SOD values at $20{ }^{\circ} \mathrm{C}$ for each designated site along the stretch of the stream. It is clear from Table 3, that each sampling site produced a range of different SOD values. For example, below Hawthorn Ditch sampling site had the highest sediment oxygen demand, while the lowest SOD values were above Canyon Lake.

\section{STATISTICAL ANALYSIS OF THE SEDIMENT OXYGEN DEMAND PARAMETERS}

In this research statistical relations between SOD values and other parameters were established using analysis of variance (ANOVA) models (Barnes,1994). Single linear and multiple linear regressions were conducted on five of the SOD sampling sites. A summary of statistical P values for single regression on depth and velocity are shown in Table 4. A summary of $\mathrm{P}$ values for multiple regression analysis for the five sites are shown in Table 5 . The purpose of the analysis was to determine which parameter is the most important variable for impact on the Sediment Oxygen Demand in Lower Rapid Creek. The following five variables were chosen for analysis: average measured water temperature $\left({ }^{\circ} \mathrm{C}\right)$, average flow velocity in the creek (ft/sec), depth of the creek at the SOD Chamber (ft), dissolved oxygen of the overlying water $(\mathrm{mg} / \mathrm{L})$, and $\mathrm{pH}$ of the overlying water. 


\section{DISCUSSION}

The outcome of ANOVA analysis on the five SOD sampling sites indicated unanimously that the depth of the creek at the chamber is the most critical variable for effect on the sediment oxygen demand, using both single and multiple linear regression analyses. For any given consistent flow rate during one sampling period through this study area, the velocity of flow would be lower for increased depth. It is conceptually expected that any given cross-section of the river should approach the conditions of an ideal settling basin, as flow velocity decrease. The better the settling conditions, the more developed the benthic layer, therefore the greater the sediment oxygen demand expected. At lower depths with higher velocities more resuspension of sediment occurs. In such a situation a greater amount of the sediment oxygen demand would be distributed to the water column and would analytically be measured as water column BOD. Therefore, it is conceptually logical that depth of the water may come out of an ANOVA analysis as the most important parameter for fully developed benthic SOD under the study conditions.

Within the range of velocities measured in this study, the $\mathrm{P}$ values for the test of significance of the regression line derived from velocity indicate that there is little confidence in rejecting the hypothesis that the slope of the regression line is not significantly different than zero. This finding implies that the relationship between velocity and SOD is not very significant. The velocity was eliminated as the least statistically important parameter when the relationship of the chosen parameters to the SOD was evaluated in a step-wise elimination in multiple variable ANOVA analysis at all of the sampled sites except for Caputa.

The applications of multiple linear regression ANOVA assumes that the variables should be independent of each other. Independence is not generically expected for velocity and depth 
relationships in a stream. However, this condition is applicable for the Lower Rapid Creek sampling sites during this study. The stretch of the study area is less than 100 miles, and the stream depth did not vary significantly at the study locations. The researchers also investigated other possible impacts on SOD including land use patterns, sediment composition, grain size analysis, and macroinvertebrate populations. The results of these investigations indicating the relationship of SOD rates to organic content, particle size, and density of macroinvertebrate populations will be presented in a future article.

The average flow velocity in the creek was identified as a variable with low significance in both single regression and multiple regression. The same results for correlation importance were achieved whether the relationship of the chosen parameters to SOD were analyzed as a single variable or were step-wise eliminated in multiple variable ANOVA analysis. These results give further empirical evidence for the independence assumption.

\section{CONCLUSION}

The analysis of variance (ANOVA) models for both single and multiple linear regression results on sediment oxygen demand parameters indicated that the depth of the creek at the chamber was the most critical variable for effect on the sediment oxygen demand. The average flow velocity in the creek was the first variable to drop out in the multiple linear regression analysis as the insignificant variable.

These results led to the conclusion that the new improvement made in this research by replacing the electrical circulation pump in the chamber (which has been commonly used to manufacture a chosen velocity in an attempt to maintain a homogenous steady mix inside the chamber) may have eliminated an experimental artifact of a velocity effect found by other 
researchers (James 1973, Whittemore 1986, James 1986, Hickey 1986). A double-sided stainless steel fan supported on a 12-inch free rotation rod passing through the top of the chamber where the natural current flows in the stream generated the rotation of the outside blades leading to a complete rotation of the inside blades was used in this research. This method developed a circulation inside the chamber depending on the actual current velocity of the flow outside the chamber. This design provided mixing which emulated the natural environmental conditions for the sediment under the chamber with less disturbance and resuspension effects than have occurred in other research due to the artificial mixing, using a water pump or motor. As a result the average flow velocity variable became an insignificant factor inside the chamber and was the first variable to drop out through the ANOVA models.

\section{REFERENCES}

- Bowman, G. T., and Delfino, J. J., (1980) "Sediment Oxygen Demand Techniques: A Review and Comparison of Laboratory and In Situ Systems.” Water Research, V.14, No. 5, 491-499.

- Barnes, Weseley, J. "Statistical Analysis for Engineers and Scientists” Mc-Graw-Hill, Inc. 1994, $396 \mathrm{P}$

- Driscoll, D. G., and Zogorski, J. S., (1990) "Basin Characteristics, History of Stream Gaging, and Statistical Summary of Selected Streamflow Records for the Rapid Creek Basin, Western South Dakota.” USGS Open file Report 90-120.

- Edberg, Nils, and Hofsten, Bengt V. (1973) “Oxygen Uptake of Bottom Sediments Studied In Situ and in the Laboratory." Water Research, V. 7, pp.1285-1294. 
- Goddard, K. E., and Lockner, T. K., (1989) "Summary of Data Pertaining to Land Use, Rainfall, Dryfall, Stream Discharge, and Storm Runoff Collected as Part of a Study of the Effects of Urban Runoff on Rapid Creek, Rapid City Area, South Dakota." USGS OpenFile Report 87-45 pp. 1-12.

- Hickey, C.W., (1986) "Chamber Studies of Benthic Oxygen Uptake Kinetics in the Waiotapu River, New Zealand.” In Sediment Oxygen Demand : Processes, Modeling, and Measurement, edited by Kathryn J Hatcher, Athens, University of Georgia Institute of Natural Resources, pp. 37-61.

- James, A., (1973) “The Measurement of Benthal Respiration.” Water Research, Vol. 8, pp.955-959.

- James, A., (1986) “Sediment Oxygen Demand in the Estuary of the River Tyne." In Sediment Oxygen Demand: Processes, Modeling, and Measurement, edited by Kathryn J. Hatcher, Athens, University of Georgia Institute of Natural Resources pp. 99-112.

- Murphy, P.J., and Hicks, D.B., (1986) "In Situ Method for Measuring Sediment Oxygen Demand." In Sediment Oxygen Demand: Processes, Modeling, and Measurement, edited by Kathryn J Hatcher, Athens, University of Georgia Institute of Natural Resources, pp. 307-322.

- Rounds, S. A. and Doyle, M. C., (1997) "Sediment Oxygen Demand in the Tualatin River Basin, Oregon, 1992-96.” USGS Report 97-4103.

- Thomann, R. V., and Mueller, J. A., (1987) "Principles of Surface Water Quality Modeling and Control" New York.

- Whittemore, R. C., (1986 b) "Problems with In Situ and Laboratory S.O.D. Measurements and Their Implementation in Water Quality Modeling Studies.” In 
Sediment Oxygen Demand: Processes, Modeling, and Measurement, edited by Kathryn J. Hatcher, Athens, University of Georgia Institute of Natural Resources, pp. 331-342.

- Ziadat, A.H., (2000) "Water Quality Assessment of Lower Rapid Creek Near Rapid City, South Dakota," PhD Dissertation, South Dakota School of Mines and Technology, Rapid City, South Dakota.

\section{ACKNOWLEDGEMENTS}

The authors would like to express their deep appreciation and gratitude to Dr. Scott Kenner for his support. Special thanks to the United States Geological Survey Office in Rapid City, the South Dakota Department of Environmental and Natural Resources. Many thanks also are extended to Joel Galloway, Ron Dell, Bob Whipple, Hopa Yellowhorse, Hayes Haas, and Jeff Jensen, for their contribution throughout this research. 


\begin{tabular}{|l|l|l|}
\hline Cross Section & $\begin{array}{l}\text { Study Average Cross } \\
\text { Section Velocity, ft/sec }\end{array}$ & $\begin{array}{l}\text { Study Average Point } \\
\text { Velocity at the Chamber, } \\
\text { ft/sec }\end{array}$ \\
\hline Above Canyon Lake & 0.86 & 0.81 \\
\hline Hawthorne & 0.95 & 0.95 \\
\hline Above WWTP & 1.16 & 1.21 \\
\hline Below WWTP & $4.18^{*}$ & 1.11 \\
\hline Caputa & 1.55 & 1.52 \\
\hline Farmingdale & 0.91 & 0.89 \\
\hline
\end{tabular}

*Large variation below the WWTP was due to WWTP discharge effects on the reach.

Table 1. Average Velocity for Cross Section and at Chamber

\begin{tabular}{|l|c|c|c|}
\hline Sampling Site & $\begin{array}{l}\text { Highest SOD Value } \\
\left(\mathbf{g} / \mathbf{m}^{\wedge} \mathbf{2 . d a y}\right)\end{array}$ & $\begin{array}{l}\text { Lowest SOD } \\
\text { Value } \\
\left(\mathbf{g} / \mathbf{m}^{\wedge} \mathbf{2 . d a y}\right)\end{array}$ & $\begin{array}{l}\text { Average SOD } \\
\text { Value } \\
\left(\mathrm{g} / \mathbf{m}^{\wedge} \mathbf{2 . d a y}\right)\end{array}$ \\
\hline Above Canyon Lake & $\mathbf{4 . 1 1}$ & $\mathbf{1 . 2 4}$ & $\mathbf{2 . 9 0}$ \\
\hline $\begin{array}{l}\text { Below Hawthorn } \\
\text { Ditch }\end{array}$ & $\mathbf{8 . 9 4}$ & $\mathbf{4 . 4 0}$ & $\mathbf{6 . 1 1}$ \\
\hline Above W.W.T. Plant & $\mathbf{6 . 1 1}$ & $\mathbf{2 . 8 7}$ & $\mathbf{4 . 4 6}$ \\
\hline Below W.W.T. Plant & $\mathbf{8 . 7 2}$ & $\mathbf{3 . 8 2}$ & $\mathbf{5 . 2 5}$ \\
\hline At Caputa & $\mathbf{6 . 9 1}$ & $\mathbf{3 . 9 6}$ & $\mathbf{5 . 4 4}$ \\
\hline Near Farmingdale & $\mathbf{7 . 4 9}$ & $\mathbf{3 . 6 7}$ & $\mathbf{5 . 3 0}$ \\
\hline
\end{tabular}

Table 2. SOD values for each site calculated at the average measured temperature.

\begin{tabular}{|l|c|c|c|}
\hline Sampling Site & $\begin{array}{l}\text { Highest SOD Value } \\
\left(\mathbf{g} / \mathbf{m}^{\wedge} \mathbf{2 . d a y}\right)\end{array}$ & $\begin{array}{l}\text { Lowest SOD } \\
\text { Value } \\
\left(\mathbf{g} / \mathbf{m}^{\wedge} \mathbf{2 . d a y}\right)\end{array}$ & $\begin{array}{l}\text { Average SOD } \\
\text { Value } \\
\left(\mathbf{g} / \mathbf{m}^{\wedge} \mathbf{2 . d a y}\right)\end{array}$ \\
\hline Above Canyon Lake & $\mathbf{5 . 1 7}$ & $\mathbf{1 . 5 0}$ & $\mathbf{3 . 8 0}$ \\
\hline $\begin{array}{l}\text { Below Hawthorn } \\
\text { Ditch }\end{array}$ & $\mathbf{9 . 3 8}$ & $\mathbf{4 . 6 0}$ & $\mathbf{6 . 9 8}$ \\
\hline Above W.W.T. Plant & $\mathbf{6 . 2 4}$ & $\mathbf{2 . 7 4}$ & $\mathbf{4 . 6 7}$ \\
\hline Below W.W.T. Plant & $\mathbf{8 . 8 1}$ & $\mathbf{3 . 8 0}$ & $\mathbf{5 . 1 8}$ \\
\hline At Caputa & $\mathbf{6 . 9 2}$ & $\mathbf{3 . 4 1}$ & $\mathbf{4 . 6 9}$ \\
\hline Near Farmingdale & $\mathbf{7 . 5 6}$ & $\mathbf{3 . 5 6}$ & $\mathbf{4 . 7 9}$ \\
\hline
\end{tabular}

Table 3. SOD values for each site calculated at the standard $20 \mathrm{C}^{0}$ temperature. 


\begin{tabular}{|l|l|l|}
\hline Station & Depth & Velocity \\
\hline Above Canyon Lake & 0.035 & 0.560 \\
\hline Hawthorne Ditch & 0.087 & 0.477 \\
\hline Below WWTP & 0.003 & 0.904 \\
\hline Caputa & 0.0004 & 0.762 \\
\hline Farmingdale & 0.018 & 0.332 \\
\hline
\end{tabular}

Table 4. P-Value Summary for Single Regression Analysis of Stated Value vs. SOD

\begin{tabular}{|l|l|l|l|l|l|}
\hline Station & $\begin{array}{l}\text { Water } \\
\text { Temp }\end{array}$ & $\mathrm{pH}$ & $\mathrm{DO}$ & Depth & Velocity \\
\hline Above Canyon Lake & 0.353 & 0.456 & 0.649 & 0.053 & 0.703 \\
\hline Hawthorne Ditch & 0.284 & 0.244 & 0.225 & 0.142 & 0.847 \\
\hline Below WWTP & 0.451 & 0.491 & 0.422 & 0.011 & 0.901 \\
\hline Caputa & 0.886 & 0.233 & 0.667 & 0.008 & 0.269 \\
\hline Farmingdale & 0.008 & 0.061 & 0.018 & 0.005 & 0.102 \\
\hline
\end{tabular}

Table 5. P-Value Summary for Multiple Regression Analysis of Stated Value vs. SOD 


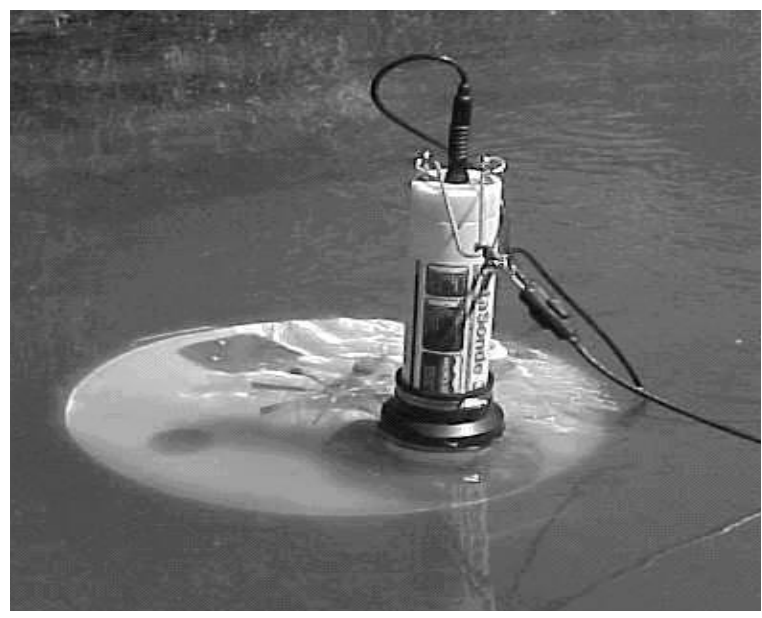

Figure 3. In-Situ SOD Chamber with Double-Sided Stainless-Steel Blades in Action. 


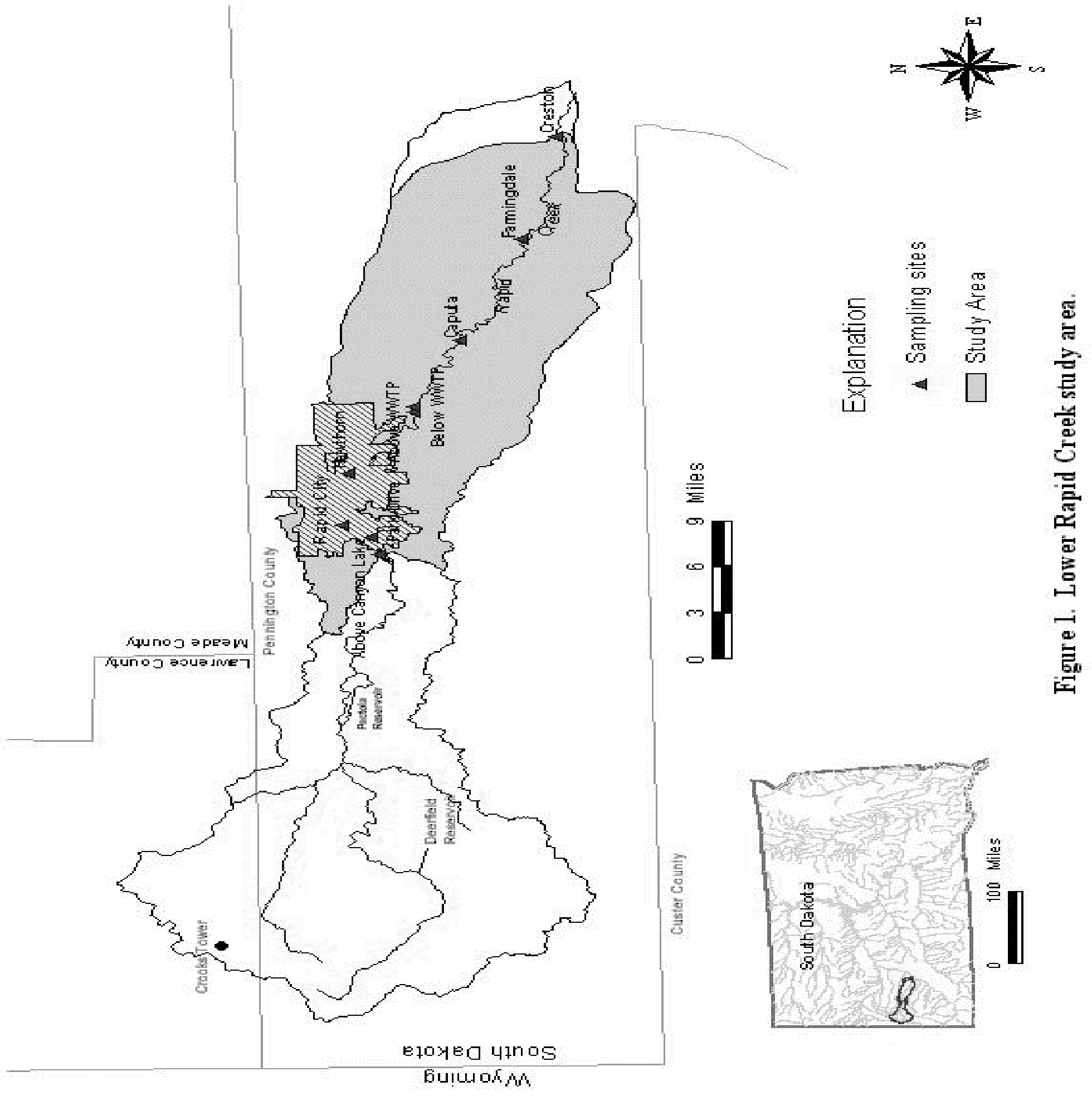




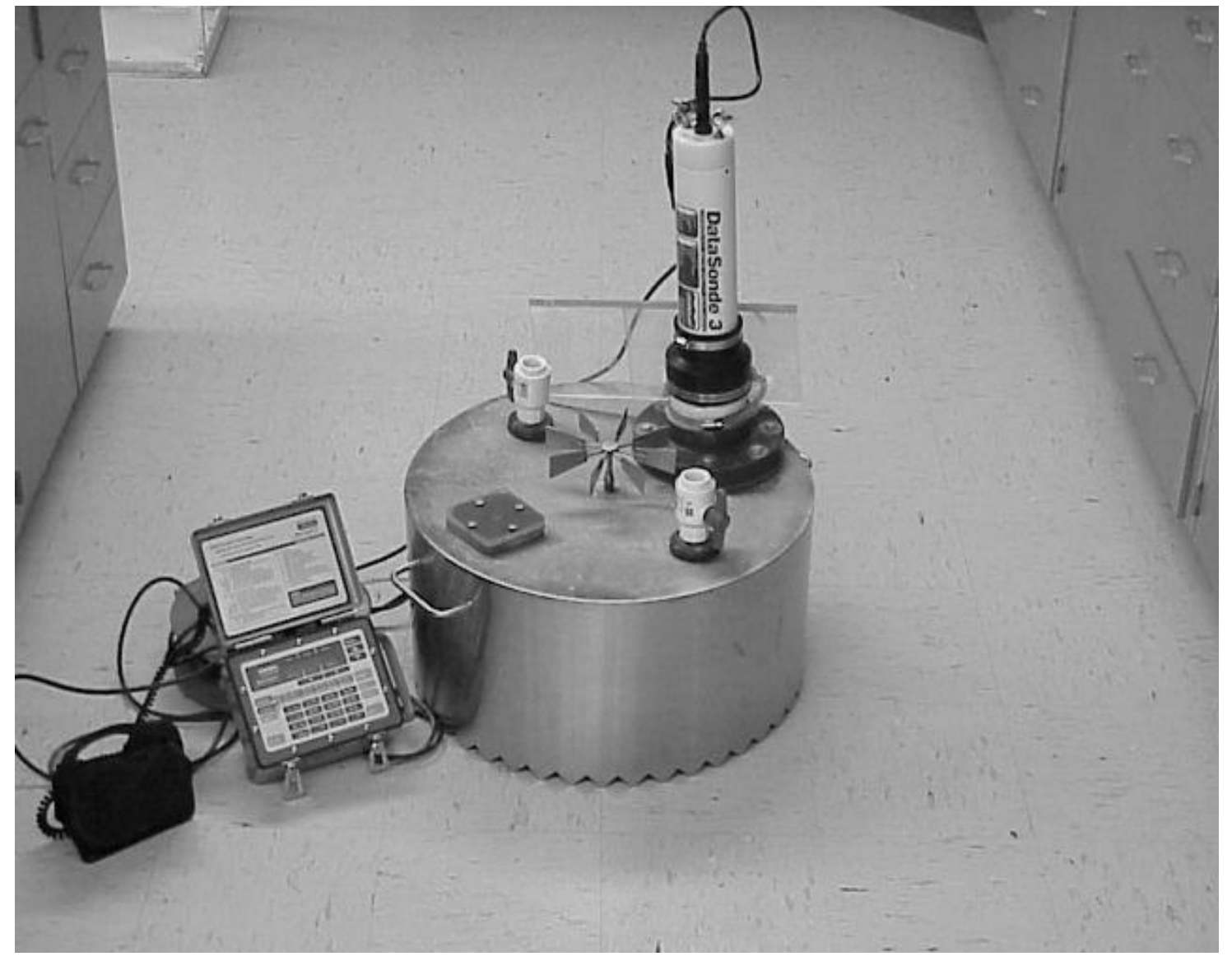

Figure 2. Sediment Oxygen Demand Chamber Connected to (SVR3 - DL) Hydrolab. 